\title{
The psychological influences on participation in Wheelchair Rugby: a social relational model of disability
}

\author{
Damian Haslett", Ben Fitzpatrick, Gavin Breslin
}

School of Sport, Ulster University, Jordanstown, United Kingdom

* Corresponding author:DXH607@bham.ac.uk

\begin{abstract}
Sport and exercise psychology research in disability sport seldom engages with social models of disability. As a result, the socio-historical landscape of disability is underrepresented in sport psychology research. The aim of this study is to interpret influences on participation in disability sport through the conceptual lens of the social relational model (SRM) of disability (Thomas, 1999, 2004, 2007). Ten Irish adult male athletes with physical disabilities participated in semi-structured interviews exploring the barriers and facilitators that influence participation in Wheelchair Rugby. Deductive thematic analysis produced four themes influenced by the social relational model: impairment effects; societal attitudes and discourse; opportunities and access; and psychological well-being. Links were made to the experience of embodied impairment, classification, oppression, inequality, media, independence, and self-efficacy. The analysis illustrates how cultural constructions of disability are inextricably linked to individual influences on participation in Wheelchair Rugby. The results indicate that in disability sport participation, the experience of social oppression, inequality and cultural stereotypes of disability can be synonymous with the personal experience of physical impairment. The implication of this research is that there is a value in sport and exercise psychology practitioners utilising the social relational model as a tool to conceptualise the lived experience of physical disability.
\end{abstract}

\section{KEYWORDS}

disability studies; spinal cord injury; disability sport; psycho-emotional oppression; para-sport

Dol

https://doi.org/ 10.14712/23366052.2017.5

(c) 2017 The Authors. This is an open-access article distributed under the terms of the Creative Commons Attribution License (http://creativecommons.org/licenses/by/4.0), which permits unrestricted use, distribution, and reproduction in any medium, provided the original author and source are credited. 


\section{INTRODUCTION}

Disability sport is becoming increasingly popular. For example, the Paralympic Games is now the second largest multi-sport event on earth (Brittain, 2016). Nevertheless, participation by people with physical disabilities in sport in local communities is less frequent than in the general population. For example, in Northern Ireland, $26 \%$ of adults without disabilities are members of sports clubs compared to $13 \%$ of adults with disabilities (Department of Culture, Art and Leisure Northern Ireland, 2015). Common individual and societal factors that influence participation in disability sport have been identified. Common barriers to participation are the disability itself, lack of accessible facilities, and societal attitudes towards those with a disability (Jaarsma, Dijkstra, Geertzen, \& Dekker, 2014). Common facilitators are improved physical health, increased social connections, and increased opportunities to get involved in sport (Jaarsma, Dekker, Geertzen, \& Dijkstra, 2016). However, there remain gaps in understanding the psychology of participation (Smith, Perrier, \& Martin, 2016), this may in part be due to studies with survey designs that often combine sports and/or disabilities and use measures that lack psychometric reliability (Jaarsma et al., 2014). Therefore, according to some researchers, there is a need for more qualitative designs in research to understand context and unpick the meaning of factors that influence participation in disability sport (Williams, Smith, \& Papathomas, 2014; Smith, Perrier, \& Martin, 2016).

Another gap in the psychological knowledge of participation is that few researchers have used evidenced based theory to add context to their results. However, some researchers have begun to address this by incorporating behaviour change theories to interpret their findings. One example is Martin (2008) who used social cognitive theory (Bandura, 1986) to show that self-efficacy is positively correlated with enjoyment and commitment in Wheelchair Basketball. In a more recent example, Jaarsma et al. (2016) related their findings to the theory of planned behaviour (Ajzen \& Madden, 1986) and argued that people who participate in sport after rehabilitation perceive more benefits (e.g. fun) than barriers (e.g. pain). The authors went on to suggest the importance of developing positive attitudes towards participation in sport. With the inclusion of a theory, this demonstrates a progressive theoretical avenue, as linking such influences to established cognitive constructs (e.g. attitudes, motivation, self-efficacy) can guide strategies to promote participation (Smith \& Perrier, 2015). Although not all researchers share this view, and have argued that behaviour change theories have limitations in disability sport research (e.g., Martin, 2013; Smith \& Perrier, 2015; Smith, Perrier, \& Martin, 2016). Smith and Perrier (2015), for example, suggest that reducing people to universal cognitive processes neglects the important socio-cultural and relational dimensions that shape the lives of people with physical disabilities. They reason that the field of disability studies is concerned with understanding the individual and the social dimensions of disability and thus offers an alternative theoretical perspective (Martin, 2013; Smith \& Perrier, 2015). In spite of these arguments, sport and exercise psychology research rarely acknowledges or incorporates models of disability (Smith, Perrier, \& Martin, 2016). Therefore, this study intends to address this knowledge gap.

There are two conventional and influential models of disability; the medical model and the social model. In the medical model (also known as the individual model), 
disability is a problem of reduced physical function and the solution is individual treatment (e.g. personal therapy, medical treatment) (Bury, 2001). This approach has been heavily criticised for painting a negative picture of disability; for example, implying that some individual's bodies are 'normal' while others are 'abnormal' (Reindal, 2010). Smith and Perrier (2015) argue that sport and exercise psychology research, that promotes disability sport for individual health, can either knowingly or unknowingly be framed in a medical model of disability. In the social model (Oliver, 2004), society causes disability through social oppression. The 'solution' is to challenge negative attitudes and breakdown restrictive environmental barriers (Shakespeare \& Watson, 2001). The implication of the social model has been liberating for people with physical disabilities, as the 'problem of disability' is viewed as socially constructed and lies outside of the individual (Reindal, 2010). Through the lens of the social model of disability, Brittain (2004) demonstrated how the media has helped to construct a 'medical model' discourse in para-sport. For example, paralympic athletes in his study reported that their sports are often perceived by the general public as a form of rehabilitation. However, and importantly, both of these models are problematic for psychological research as they each undervalue important experiences of disability (i.e. the experience of social oppression or the experience physical impairment) (Smith \& Perrier, 2015).

The social relational model (SRM) of disability (Thomas, 1999, 2004, 2007) is a conceptually progressive model that explains disability as the experience of socialised impairment. This conceptualisation can overcome the limitations of previous models by recognising that impairments have direct and immediate effects (e.g. reduced function, physical weakness) and that, at the same time, socially-engendered restrictions can arise in different forms (e.g. structural and attitudinal) (Goodley, 2013). Thomas (2007) calls these the psycho-emotional dimensions of disability. By privileging disability as an experience of restrictions the SRM can help to understand the interplay of individual and societal influences on participation in disability sport (Martin, 2013). In the SRM, the concepts of impairment and disability are manifestations of social relationships, produced as people engage in social structure (order) and social agency (action) (Thomas, 2004). Reduced physical function is a necessary condition for the possibility of various forms of social oppression (e.g. cultural assumptions of disability) that can arise at different times and in different places for different people (Goodley, 2013) (see Figure 1).

In the SRM, four social contexts are identified where the experience of disability can arise (Goodley, 2013; Thomas, 2004). Restrictions can arise from the immediate everyday physical and social influence of physical impairment (e.g. chronic pain or the need for time and social support). Thomas (2004) calls these impairment effects (see Figure 1, Point 2). Restrictions can also arise directly from negative experiences of cultural constructions of disability (see Figure 1, Point 3 (b)) (e.g. having to deal with negative societal attitudes and discourse, such as being perceived as unfortunate). These types of negative interactions fall under the concept of direct psycho-emotional oppression. Furthermore, restrictions can arise indirectly from the experience of structural disablism (see Figure 1, Point 3 (b)). That is, being excluded from opportunities and services (e.g. the anger and frustration of inaccessible buildings). These negative interactions with the structural environment are examples of indirect psycho-emotional oppression. Finally, restrictions can be self imposed if psycho-emo- 


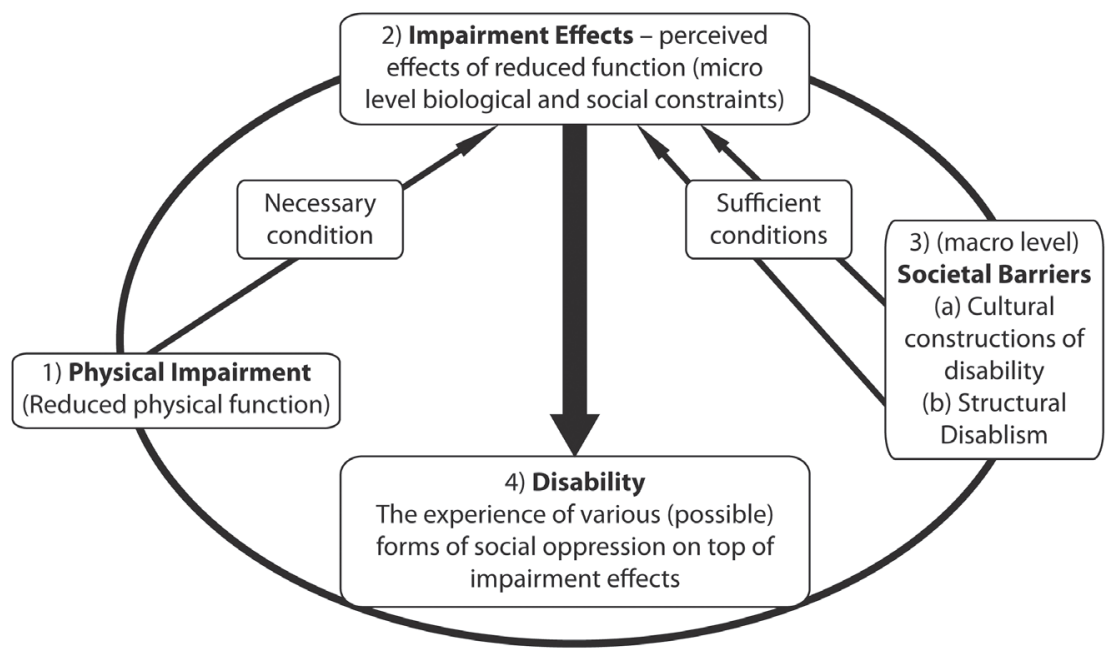

Figure 1 Impairment in context: A Social Relational Model of disability (Thomas, 1999, 2004, 2007); adapted from Reindal (2008)

tional well-being is undermined (Thomas, 2004). Repeated exposure to negative interactions with the social and built environment can result in people placing limits on what they can do and what they can become (e.g. avoid participation in sport). For example, confidence and self-esteem can be damaged as a result of internalising negative cultural stereotypes of disability (e.g. passive, weak or dependent).

The SRM is not a psychological model, it has been developed through sociological research (Thomas, 1999). And the psychological constructs of the SRM (e.g. psycho-emotional oppression) have little empirical evidence in disability sport (Smith \& Perrier, 2015). However, Martin (2013) has used the SRM to exemplify some of the paradoxes and nuances in psychological research into barriers to participation in disability sport. In a review of selected articles on barriers to participation, he argued that physical, social and environmental barriers are inextricably linked. For example, the 'barrier' of a person in a wheelchair unable to get up a ramp can be located simultaneously in the individual (I don't have the strength), the social (I don't have the help), or the environmental (the ramp is badly designed) (Martin, 2013). Furthermore, the SRM has been utilised to develop psychological knowledge in areas outside sport; for example, as a theoretical framework that accounts for individual differences as well as the experience of oppression in special needs education (Riendal, 2008). In another example, the SRM has been used to offer an alternative way of conceptualising Parkinson's Disease, by showing how stigmatising attitudes have contributed to the experience of physical restrictions (Simpson, McMillan, \& Reeve, 2013).

As of yet, no study has applied the SRM to investigate the psychology of participation in disability sport. The aim of this study is to interpret participation in Wheelchair Rugby through the conceptual lens of the SRM. The context of Wheelchair Rugby was chosen as, in Ireland, the sport has low participation levels (e.g. 38 players). The objective of the study was to explore the interplay of individual and societal facilitators and barriers to participation in Wheelchair Rugby. 


\section{METHOD}

This study employed a qualitative research approach using one-to-one semi-structured interviews with Wheelchair Rugby athletes. To reflect the idiosyncratic nature of this methodology and a conceptual framework that foregrounds the influence of social relationships, a relativist ontology and constructionist epistemology was adopted. This involves an assumption of reality as mind-dependent and that the path to knowledge is similarly subjective and value-laden (Smith \& Caddick, 2012). These assumptions inform an interpretivist paradigm where researchers attempt to make meaning of human experience through interaction with participants.

\section{Ethics Statement}

Ethical approval was granted from the lead institution (Ulster University, School of Sport Research Ethics Filter Committee) on 8th Jun 16 (Ref- MSc186 2015/16). All participants provided written informed consent.

\section{Participants}

Wheelchair Rugby athletes were recruited as they have personal experience and opinions on the individual and societal influences on participation. Wheelchair Rugby is a mixed-gender sport played in over 40 countries for people with physical impairments that affect the arms and the legs (www.iwrf.com). The goal was to involve the maximum variation in experiences and opinions of active athletes. Criteria for inclusion were (1) one-year post injury (2) aged over 18 years and (3) actively engaged in Wheelchair Rugby (30 minutes at least twice a week). At the time of this research, within Ireland, there were 38 athletes in four clubs (www.irishwheelchairrugby.com). Ten male athletes from three clubs took part in this study $\left(M_{\text {age }}=33.1\right.$ years, age range: 22-53 years). Nine participants in this study had spinal cord injury and eight athletes described themselves as having an acquired disability. Six participants disclosed that they had played sport prior to injury. Participants had played Wheelchair Rugby from between 1.5-19 years and seven had played at an International level. The participant pool represented every Wheelchair Rugby classification group between 0.5 (lowest function) and 3.5 (highest function).

\section{Data Collection}

Data was collected through face-to-face interviews with the aim of capturing the experience and opinions of participants in wheelchair rugby participation. A semi-structured interview guide was developed based on the components of the SRM (Thomas, 2004). For example, questions addressed the influence of immediate effects of impairment (e.g. how do you think that different impairments restrict participation?), cultural representations of disability (e.g. do stigmatising attitudes affect participation in Wheelchair Rugby?) and the structural environment (e.g. how does access to sport facilities influence participation?). Questions were designed to allow topics to be explored in a variety of ways while ensuring that systematic lines of inquiry were followed with each interview. The interview guide was pilot-tested with an academic researcher and an active female Wheelchair Rugby player. After each test the guide was adapted and improved in order to be able to best capture interviewees' meanings. 
For example, the specific words 'barriers' and 'facilitators' were found to be confusing and consequently removed from all questions. The final version of the interview guide was applied to all interviews (see Appendix A).

Participants were identified via purposeful sampling and recruited by the primary researcher who works in a voluntary capacity with Irish Wheelchair Rugby. The primary researcher is not a wheelchair user and has experience using qualitative research methodologies with visually impaired athletes. Participants were provided with details of the research project via-email to confirm that they met the criteria for inclusion. Interviews were organised at suitable locations (e.g. wheelchair accessible hotel lobbies) and began with an informal conversation aimed at relaxing the interviewee. Curiosity-driven prompts were used to focus on topics relative to the research aims (e.g. can you give me an example of that experience?). All interviews were recorded (Sony ICD-PX440) and ranged from $30 \mathrm{~min}$ to $55 \mathrm{mins}$ (avg $39 \mathrm{mins}$ ). Interviews were transcribed verbatim yielding 121 pages of data (single-line spaced). As there was no new experiences or opinions about the research aims after the tenth interview, saturation was deemed to be achieved.

\section{Data Analysis}

Deductive thematic analysis was used to interpret and construct themes within the data (Smith \& Caddick, 2012). A code book (see Appendix B) was developed based on the research objectives and the four social contexts of the SRM (Thomas, 1999, 2004, 2007; Goodley, 2013; Smith \& Perrier 2015; Reindal, 2008). The code book, for example, was used to attend to data related the influences of physical impairment, disability stereotypes, inaccessible environments and psychological factors such as self-esteem or confidence. As the SRM has had little use in disability sport research, several inductive and open codes were added to the code book during preliminary analysis; for example, the experience of positive cultural representations of disability sport or positive social interactions that facilitate participation in Wheelchair Rugby.

Braun and Clarke's (2006) six phase heuristic was used as a guideline to identify and interpret common themes across the data. The first phase involved 'data familiarisation' by re-reading and re-listening to transcripts (initial ideas were noted). In the second phase, the primary researcher systemically coded features of the data across the entire data (using the code book). In the third phase, potential themes were identified and data relevant to each theme were gathered. The fourth phase involved reviewing themes; similar themes were combined and specific themes were divided into new themes. The fifth phase involved defining themes; clear and distinct definitions for each superordinate and all sub-themes themes were generated. Finally, vivid quotes were chosen to exemplify themes and analysis was related back to the research aims and the social relational model. Importantly, this was circular process whereby phases were re-visited several times during analysis. NVIVO software was used to facilitate organisation of the data and to visualise relationships between codes, sub-themes and superordinate themes.

\section{Trustworthiness}

Procedures were employed to ensure that accurate and rigorous results were reported. Firstly, participants were provided the opportunity to add, clarify and authenticate their transcripts. One participant clarified a response; all participants indicated their transcripts were accurate. Secondly, to enhance researcher decision making, a re- 
flexive journal was used to record ongoing thoughts and ideas throughout the data collection and analysis process. Thirdly, to triangulate the analysis, the primary researcher presented emergent themes to an accredited sport and exercise psychologist and a disability sport researcher to dispute, support or reject. This process resulted in a consensus of themes and sub-themes. Finally, extensive quotations have been used in this report to illustrate participants' meanings (Smith \& Caddick, 2012).

\section{RESULTS AND DISCUSSION}

Four superordinate themes emerged (see Table 1). Each superordinate theme was influenced by the four contexts representing the experience of disability as conceptualised by the social relational model (Thomas, 1999, 2004, 2007). Within each superordinate theme, there are a number of sub-themes containing barriers and facilitators that influence participation. To provide insight into participants' experiences, the

Table 1 Summary of themes

\begin{tabular}{|c|c|c|c|}
\hline Superordinate Themes & Sub-Themes & Participant Quote & $\begin{array}{l}\text { Factors that Influence } \\
\text { Participation }\end{array}$ \\
\hline \multirow{3}{*}{ Impairment effects } & Physical body & $\begin{array}{l}\text { "Any bit of strength I got, I got it from } \\
\text { Wheelchair Rugby"(John) }\end{array}$ & $\begin{array}{l}\text { secondary health condi- } \\
\text { tions, health benefits }\end{array}$ \\
\hline & Needs and requirements & $\begin{array}{l}\text { "Some people don't drive, and they } \\
\text { don't have money, so then you're } \\
\text { dependent on people" (Connor) }\end{array}$ & $\begin{array}{l}\text { time, money, social } \\
\text { support, transport }\end{array}$ \\
\hline & Classification & $\begin{array}{l}\text { "Who are we to pick and choose to } \\
\text { play [Wheelchair Rugby]?" (Jack) }\end{array}$ & eligibility ambiguity \\
\hline \multirow{2}{*}{$\begin{array}{l}\text { Societal attitudes and } \\
\text { discourse }\end{array}$} & Attitudes of others & $\begin{array}{l}\text { "In Ireland [people with spinal cord } \\
\text { injury] kind of get locked away in } \\
\text { a cupboard" (Brian) }\end{array}$ & $\begin{array}{l}\text { families, medical profes- } \\
\text { sionals, teachers, general } \\
\text { public }\end{array}$ \\
\hline & Media representation & $\begin{array}{l}\text { "There's always this kind of'super } \\
\text { human' aspect of [disability sport], } \\
\text { which is wrong" (Barry) }\end{array}$ & $\begin{array}{l}\text { facilitating media, misrep- } \\
\text { resenting media }\end{array}$ \\
\hline \multirow[b]{2}{*}{ Opportunities and access } & Structural barriers & $\begin{array}{l}\text { "There's no gym that's 100\% wheel- } \\
\text { chair friendly" (Connor) }\end{array}$ & $\begin{array}{l}\text { access to rugby, general } \\
\text { access }\end{array}$ \\
\hline & Perceptions of inequality & $\begin{array}{l}\text { "A lot of people say that we are } \\
\text { discriminated against. I don't look at it } \\
\text { like that at all" (Karl) }\end{array}$ & funding, minority sport \\
\hline \multirow{3}{*}{ Psychological well-being } & $\begin{array}{l}\text { Internalising negative } \\
\text { stereotypes }\end{array}$ & $\begin{array}{l}\text { "People struggling to think that } \\
\text { wheelchair sports are for them. Not } \\
\text { because of others' attitudes but } \\
\text { because of their own attitudes" (Karl) }\end{array}$ & $\begin{array}{l}\text { self restrictions, medical } \\
\text { model assumptions }\end{array}$ \\
\hline & Independence & $\begin{array}{l}\text { "I would probably be more inde- } \\
\text { pendent than a lot of other people } \\
\text { who would have the same level of } \\
\text { function" (Barry) }\end{array}$ & $\begin{array}{l}\text { incidental learning, sense } \\
\text { of community }\end{array}$ \\
\hline & The rugby wheelchair & $\begin{array}{l}\text { "If you put them in the [rugby] chair } \\
\text { they won't get out. You kind of have to } \\
\text { experience it" (Rossa) }\end{array}$ & stress relief, confidence \\
\hline
\end{tabular}


themes are discussed with supporting quotes. To ensure anonymity, pseudonyms for each participant have been inserted.

\section{Impairment Effects}

This theme describes how the immediate day-to-day experience of impairment can influence participation. In terms of the SRM, this reflects the lived (biological and social) experience of impairment (Smith \& Perrier, 2015). Participants discussed the influence of the 'Physical body', 'Needs and requirements' and 'Classification'.

'Physical body' refers to how participants characterised the influence of secondary health conditions and physical health benefits. These factors have been found to influence participation in disability sport (Williams et al., 2014). However, little is known as to why and how these factors influence participation in Wheelchair Rugby. A number of athletes explained why health conditions can restrict participation. For some people, physical weakness or 'bowel and bladder' complications can take years to manage. For others, weight gain from post injury inactivity can restrict participation in sport. All athletes emphasised the physical benefits of Wheelchair Rugby. It can improve balance, mobility and arm strength, required to benefit life outside sport; for example, pushing day-chairs, or transferring from car to chair. As one athlete stressed "every bit of strength I got, I think it is from Wheelchair Rugby" (John).

'Needs and requirements' reflects the participants' accounts of how individual differences in the need for time, finance, transport and support, can influence participation. Athletes described how there are few Wheelchair Rugby clubs in the country (i.e. there are no clubs in the West of Ireland) and that different impairments can mean different social effects for different people. For example, athletes reported that many people with spinal cord injury are unemployed, those who can't drive often rely on family, and some people rely on carers. Depending of the level of impairment, some people could not work full time and play rugby, whereas others describe themselves as completely 'independent'. Conceptualising the factors 'time', 'finance', 'transport' and 'support' as day-to-day impairment effects is useful. This can allow research to attend to effects of changes at an immediate social level (Reindal, 2008) (Point 2 in Figure 1), that is in contrast to changes at a wider societal level (e.g. social attitudes, social inclusion) (Point 3 in Figure 1). The concept of 'additionality' (Norwich, 2002), borrowed from adapted education research (Reindal, 2008), can help understand individual differences in needs to participate in sport. For example, additional requirements such as technological (e.g. adapted cars), medical (e.g. drugs) or social support (e.g. carers) can be common, shared or unique across a group of people with similar impairments (Reindal, 2008).

'Classification' reflects the participants' descriptions of why the eligibility criteria to play Wheelchair Rugby can enhance but also restrict participation. Many participants described how Wheelchair Rugby is the ideal sport for people with tetraplegia (quadriplegia) and that the game suited the level of function that comes with this physical impairment. However, the analysis indicated an ambiguity amongst athletes about who should and who can play Wheelchair Rugby. Some athletes expressed concern for the 'new impairments' entering the game (e.g. amputees); for example, one athlete said: "You see guys walking around and that's sort of, that doesn't seem fair, you know, when it was started for quadriplegics" (Aiden). Another athlete argued 
that if the game is to grow: "Who are we to pick and choose [who can play]?" (Jack). One player even expressed concern for prejudice within the sport: "It's meant to be inclusive, you know, [but] I don't think it's fully inclusive” (Simon). Altmann, Hart, van Limbeek and Vanlandewijck (2014) provided evidence for wide scale dissatisfaction about the current classification system in the Wheelchair Rugby community (e.g. $60 \%$ of respondents disagreed that eligibility should only be open to people with tetraplegia). However, in their study, vital aspects of athletes opinions were missed as they used a questionnaire with dichotomous questions. The finding from the present study adds an athlete narrative to the literature (e.g. descriptions of why eligibility ambiguity can influence participation). This can assist the International Wheelchair Rugby Federation's aim of developing an evidence-based Wheelchair Rugby classification system (Altmann et al., 2014) that considers the opinions of athletes.

\section{Societal attitudes and discourse}

This theme describes the influence of societal attitudes and cultural representations of disability and disability sport on participation. Participants discussed the influence of 'Attitudes of others' and 'Media Representation'.

'Attitudes of others' reflects the participants' descriptions of why societal attitudes can influence participation. Athletes frequently described how patronising and ill-informed remarks from the general public can put people off sport. They spoke of the annoying and unwanted "sympathy card" (Connor) for playing sport. One athlete describes: “There's always 'oh aren't you brilliant, you're playing [...] isn't that great, you're bashing into people”" (Barry). He then goes on to explain:

There's a general consensus of disability sport as tokenism. Like 'it's great that you're getting out and you're playing something and you're doing something'. Whereas that's not the reason we're doing it [...] I've had a lot of people misunderstand disability sport, in particular Wheelchair Rugby (Barry).

In addition, some athletes spoke of the effects of being mistaken for people with intellectual disabilities; for example:

I don't know how many times people had turned around and said - 'are you going to the Special Olympics this year?' talking about Rio coming up. Nothing against mental disabilities, absolutely not, but that's fucking jeez, that gets under my skin like (Connor).

Athletes emphasised how these negative interactions are often unintended but can still has have effects. One athlete responds to the question; Do you think that discriminatory attitudes or stigmatising attitudes have an effect on participation in Wheelchair Rugby?

It is hard to say like, discrimination to some degree is there, even if it is subconscious. I think like when I am going down the street, people will give me a look or 'oh do you need help' and stuff like this, that is not them being mean or that's not them like purposely trying to discriminate but innocently giving me a look. Or when I say 'Wheelchair Rugby, I play for Ireland' and they are 'oh that's amazing, that's inspirational'. I'm not 
inspirational, like I play a sport, I have always got the crap, because mine's a physical disability. People have depression, people have family bereavements, people can't see, but because mine is a physical obvious thing you can see. It shouldn't affect how people see my sport ( Jack).

Stephens, Neil and Smith (2012) argue that these unhelpful societal attitudes stem from a lack of public awareness of participation in disability sport. In the SRM, direct psycho-emotional oppression (Thomas, 2004) is a form of social oppression that arises directly from negative social interactions between able-bodied and people with disabilities. For example, being repeatedly defined by disability, having to deal with (unintended or intended) hurtful words, or being stared at by others can effect how people view themselves (e.g. inferior). Linking these interactions to a theorised construct is useful, as research can attend to the influence of particular social interactions. For example, athletes in this study spoke of the influence of more personal negative social interactions. They spoke of how overprotective parents, overly cautious medical professionals, and ill-informed school guidance councillors can push people away from sport. In addition, athletes mentioned how positive social interactions can facilitate participation, such as Wheelchair Rugby staff (non-disabled) who can 'deal with' people with physical disabilities.

'Media representation' reflects the participants' perceptions of how the media influences participation All athletes highlighted how the coverage of London Paralympics 2012 has been 'massive' for para sport. One athlete elucidates:

I think after London [2012], GB got a big wave of players. I think so, they got a lot of clubs now, they have a lot of money. But like we got [a player] after London. You know, If you think of it, if you have a disability and you are a young guy and you turn on the TV and there is a guy with the exactly the same disability as you, flying about the place, you know, in front of 10,000 people, you would be crazy not to want to play!! (Jack)

However, in addition, athletes warned of the condescending 'super human' stereotype often used in the media to portray disability sport. The particular concern was how portraying participation in recreational sport as somehow 'inspirational' can influence attitudes of people with and without disabilities. Another athlete explains why:

You know that Guinness Ad that ran there a couple of years ago? The 'life is more', ad? I found it condescending and it just really misrepresented disability sport. If you think of it- so there was one Wheelchair User, and he was playing the sport, and then he had a couple of [non disabled] friends who were joining in. At the end they all stood up and they were being applauded for taking part in disability sport, you know yourself $-[\ldots]$ you don't do it [play sport] to be applauded or to get a pat on the back (Barry).

The Paralympic paradox, according to Purdue and Howe (2012), describes the finding of an apparent contradiction in the para-sport community about the emphasis that 'the disability' should be given in coverage of Paralympic sport. One argument is that 
the stigma of 'otherness' can be broken down by media portrayals that focus on the sporting aspects of identity; this in turn can encourage participation. The other argument is that participation can be encouraged when people identify with an impairment (Purdue \& Howe, 2012). There is evidence that viewing people with disabilities involved in sport can aid in undermining negative disability stereotypes (i.e. frail and dependent) for people without disabilities (Kittson, Gainforth, Edwards, Bolkowy, \& Latimer-Cheung, 2013). This theme adds to Shirazipour, Sweet, Perrier, Ginis and Latimer-Cheung's (2015) argument that there is a need to understand how the status of disability, as portrayed by the media, influences participation (e.g. superhuman qualities or human story characteristics). Interestingly, some athletes in this study described how social media videos are useful for raising awareness as they can show a true representation of the sport.

\section{Opportunities and accessibility}

This theme describes the influence of socio-environmental factors on participation. Participants discussed the influence of 'Structural barriers' and 'Perceptions of inequality'.

'Structural barriers' reflects the participants' perceptions of how negative interactions with the built environment can restrict participation. All athletes explained how the lack of opportunities (e.g. few clubs and suitable facilities in the country) is a major frustration. They explained how nearby facilities can attract players by reducing travel costs and the reliance on support. Moreover, athletes described how many inaccessible environments can create exclusion. For example, inaccessible Gaelic football grounds, or being split-up from (non-disabled) friends at Rugby games, can put people off sport. One athlete describes his experience of gyms;

In this country we're majorly behind on a lot of places [...] the gym I go to is [supposed to be] ' $100 \%$ wheelchair friendly'. [but] There's no gym that's $100 \%$ wheelchair-friendly [...] not one of them knows a thing about wheelchairs and then you're explaining the whole lot. So that would definitely turn off somebody from going to the gym that say didn't know much about it themselves even, or that was maybe a bit self conscious and wouldn't ask for help and would use it (Connor).

Richardson, Smith and Papathomas (2016) have researched barriers to attending gyms for people with physical disabilities and describe this type of negative experience as 'disabling messages from the physical environment'. In the SRM, this theme is evidence for the influence of indirect psycho-emotional oppression (Thomas, 2004) to participation in Wheelchair Rugby: that is, possible anger, frustration, and feeling lesser value as a result of the repeated experience of Structural Disablism (exclusion from opportunities due to 'able-bodied' power) (Goodley, 2013). A recent study identified organizational stressors across 34 competitive sports (e.g. logistics, leadership) (Arnold, Fletcher, \& Brown, 2016). However, it failed to include any disability sports. The present study adds 'the negative experience of inaccessible environments' as a distinct stressor in Wheelchair Rugby.

'Perceptions of inequality' reflects participants' views on the influence that discrimination has on participation. The majority of athletes provided examples of why 
they perceived 'able-bodied' sport as getting preferential treatment. Athletes cited perceived inequalities such as high unemployment rates, limited interest from politicians, minimal opportunities for young people, and minimal corporate sponsorship opportunities. One athlete argues:

It's unfair because they are always saying everything is equal, there is no discrimination.

But then you try to get funding and its - 'oh no, you are a para-sport, you're not getting funding from us'. It's tough, it's very tough, especially with the cost involved (Brian).

However, in a counter to this view, a few athletes insisted that there was no inequality. They took the view that Wheelchair Rugby is just a relatively new, niche and expensive sport that is fighting for recognition like any other small sport. One athlete explains:

A lot of people say that we are discriminated against. I don't look at it like that at all. It's just numbers. It's about trying to get more people involved. We are a small number. We are a minority sport. You ask the question - should we have more money? It is easy to say - yes, we should - but it is not that simple. There is $\mathrm{X}$ amount of money and it has to be spent across bigger organizations with more push and more numbers. I don't look at it in that way. I wouldn't go down the discrimination thing. For example, there are little able-bodied sports out there, judo clubs, who would be treated in the same way (Karl).

This sub-theme is pursuant to the finding by Smith, Bundon and Best (2016) that Paralympic athletes hold different orientations towards advocating change to reduce social inequality. They found that all 36 elite para-athletes in their study were concerned with advocating change within disability sport, such as perceived inequalities between able-bodied sport and disability sports. However, only seven athletes were concerned with challenging inequalities outside sport. For example, one reason is that participants thought that in general people are treated equally in society. Smith, Tomasone, Latimer-Cheung and Martin Ginis (2015) suggest that sharing stories of perceived inequalities can help expand the menu of narrative recourses across a group of athletes with disabilities. This process can facilitate dialogue to improve well-being and tackle inequalities in sport (Smith et al., 2015). However, contrary to this theme, it is important to note that some athletes did not hold any views about inequality.

\section{Psychological Well-Being}

The final theme describes the influence of autonomy and self-restrictions on psychological well-being. Participants discussed the influence of 'Internalising negative stereotypes', 'Independence' and 'The rugby wheelchair'.

'Internalising negative stereotypes' refers to the participants' descriptions of selfrestricting behaviour from internalising different forms of social oppression. Athletes spoke of how people with spinal cord injury often don't leave their homes. They indicated that this could be because they 'feel inferior', or they have lost their social circle, or they are afraid to get injured again. Other reasons for not participating is some people focus time and resources on the often unattainable goal of walking, or that people might not 'lower' themselves to play wheelchair sports. Feelings of low self-worth as 
a result of acquired spinal cord injury can restrict participation in sport (Smith, 2013). In the SRM, internalised oppression can result in people placing self-imposed limits on what they can do (Thomas, 2004). Repeated exposure to dominant 'medical model' understandings of disability (e.g. unfortunate or defined by impairment) can damage self-esteem (i.e. feeling lesser value) (Goodley, 2013). One athlete quote illustrates how negative cultural attitudes can lead to self-restricting behaviours:

The main one would be depression, especially in people with spinal cord injuries, especially in Ireland, they kind of get locked away in a cupboard. Especially if they are from rural kind of counties, they wouldn't go out or anything. Especially if they were playing sport before their accident, then they get injured and like - 'oh, there is no point in me doing sport anymore, I'm never going to be as good as what I was'. Whereas they could be the next world champion for all we know (Brian).

'Independence' reflects participants' perceptions on why increased autonomy can facilitate participation. All athletes spoke avidly about how involvement in Wheelchair Rugby can contribute to independent lives. Athletes described how people with similar stories fashioned a sense of community and family. Moreover, all athletes emphasised the importance of learning 'little things' of each other that can help in daily life. Such as, using day chairs correctly, emptying leg bags, transferring chairs, driving, picking up a bottle of beer and eating. One athlete recounts a story that exemplifies the importance of being around people with similar impairments:

So you get to the hotel and - 'shit, how am I going to shower?' And then you realise - ah well, I'll ask one of the lads, [...] and he said 'just get into the bath'. And I said 'how am I going to get into the bath!?' So then basically he comes, 'I'll show you'. I had a look at him getting into the bath, obviously not into the bath naked, but into the bath, [and then I followed] how he done it (Connor).

This theme confirms the finding of Stephens et al. (2012) that incidental learning (learning from others) in disability sport is an important influence in becoming more autonomous in life. Enhancement of autonomy is understood to be an important influence in self-determined motivation to participate in sport (Deci \& Ryan, 2000). The common experiences and emotional connections that are found in Wheelchair Rugby can benefit psychological well-being (Goodwin, Johnston, Gustafson, Elliott, Thurmeier, \& Kuttai, 2009). This suggests that 1) role models are important in facilitating participation and 2) enhancement stories of empowerment can be used as a narrative recourse to counter fears (e.g. worried parents) and influence participation (Goodwin et al., 2009).

'The rugby wheelchair' reflects the participant's descriptions of how the experience of the rugby chair can facilitate participation. Quotes from the athletes such as, "once you get into the chair I think you've automatically got people" (Aiden) and "If you put them in the chair they won't get out" (Rossa), describe how the chair is often the trigger to participation. A number of athletes stressed that a sense of empowerment and confidence can be installed in people when they realise that they have the ability to play Wheelchair Rugby, as one player said: 
There is that stigma as well with [disability], like, 'oh, I'm in a wheelchair and I can't do anything now - my life is over'. Then they come to sport and they see all the lads bashing each other and they are like, hang on a minute, if they can do that I can do that. Then I think that stigma kind of goes, with that person (Brian).

Moreover, players discussed how playing rugby is great stress relief, for example: "Just the buzz of getting into a rugby chair, pushing the shit out of it and smashing other lads [...] Just where my head goes when I'm playing [Wheelchair Rugby]. You just get into it" (John). Martin (2008) had provided evidence for a relationship between confidence in ability (self-efficacy) and commitment to playing Wheelchair Basketball. Litchke et al. (2012) found that Wheelchair Rugby athletes associate a deep meaning with the 'hard hitting' and 'maximum power' aspects of the sport. They argue these aspects run counter to the conventional disability image (e.g. weak and frail). The finding from the present study fits with ideas from social cognitive theory (Bandura, 1997), by suggesting that the rugby chair can play in important role in the interaction of personal, behavioural and environmental influences on perceived capabilities (self-efficacy). This in turn can influence participation in Wheelchair Rugby.

\section{SUMMARY}

The aim of this research was to interpret the factors that influence participation in disability sport through the conceptual lens of the social relational model of disability (Thomas, 1999, 2004, 2007). The results provide new evidence in support of the SRM as a heuristic to investigate participation in disability sport. By foregrounding disability as an experience of socialised impairment, categorising influences as either individual or societal does not do justice to the lives of people that are simultaneously shaped by restrictions in society and restrictions imposed upon by society. For example, weakness or lack of time can be individual barriers to participation and, at the same time, socially imposed barriers (e.g. limited accessible facilities). Similarly, cultural assumptions about the meaning of physical disability and disability sport can influence how people feel about themselves (e.g. confidence) and behave (e.g. participate in Wheelchair Rugby).

The specific research objective was to explore the interplay of individual and societal barriers and facilitators to participation in Wheelchair Rugby. As described, individual and societal factors that influence participation in Wheelchair Rugby are inextricably linked. Barriers and facilitators come in the form of (1) direct physical and social effects of impairments, such as the experience of secondary health conditions or perceptions of classification, (2) social interactions, such as the experience of cultural attitudes and discourse about disability and disability sport, (3) structural barriers, such as limited sport opportunities and social inequality and finally (4) psychological well-being, such as increased autonomy through involvement in Wheelchair Rugby or the influence of the rugby wheelchair on confidence.

Taken collectively the current findings support some researcher's arguments that disability sport research is at times framed in a medical (or individual) model of disability (Smith \& Perrier, 2015). As psychological research often promotes sport for health benefits, barriers to participation are implied as problems to overcome. 
And some studies (justifiably) report 'the disability itself' or 'their disability' as personal barriers to participation in sport (e.g. Jaarsma et al., 2014; Jaarsma et al., 2016). Moreover, research that promotes participation based on cognitivist behaviour change theories, such as self-determination theory (Deci \& Ryan, 2000), can imply that there is an individual responsibility to participate in sport. The importance of societal influences (e.g. lived experience of disability) gets undervalued in research (Smith \& Perrier, 2015). Detrimentally, those who do not participate can be perceived by some as lacking in individual qualities (e.g. motivation, attitude, self-efficacy) (Smith \& Perrier, 2015).

The current study has a number of strengths. It is novel in that it is the first study to use the SRM as a conceptual framework to investigate the psychology of participation in disability sport. The SRM can help psychologists to attend to the effects of contemporary issues in disability sport; such as perceptions of classification, inequality, and media representation. Linking the disciplines of critical disability studies with sport and exercise psychology can help to expand ways of knowing and allow researchers to think differently. For example, by giving weight to the lived experience of disability this approach honours how the experience of reduced function can also enrich lives. Furthermore, this research has been methodologically strengthened by a large sample size, that is $25 \%$ of current Wheelchair Rugby athletes in Ireland were interviewed. This study also has limitations. The psychological constructs of the SRM (e.g. psycho-emotional oppression) still lack empirical evidence in the context of sport. That is in contrast to established psychological constructs backed with empirical evidence in sport, such as the constructs 'autonomy' or 'competence' from self-determination theory (Deci \& Ryan, 2000). Although the SRM foregrounds disability as an experience, more weight is given to how negative interactions (social and structural) can damage psychology (e.g. self-esteem and confidence) than to how positive interactions can have psychological benefits. In this sense, a progressive conceptualisation of disability has been favoured over the influence of universally assumed evidence based psychological constructs (e.g. self-efficacy or competence). There was also a methodological weakness. Interpreting data according to the SRM produced an analytical task to separate restrictions in society from restrictions imposed upon by society. This task is particularly challenging using a qualitative methodology. Interpreting a social interaction, for example, as 'socially engendered discrimination' can depend on the political orientation of the researcher.

Future studies should be conducted that focus on the intersection of ideas from social models of disability with behaviour change theories (e.g. self determination theory). Researchers should test the SRM as a tool to inform psychology in other areas of disability sport, such as the experience of transitions out of sport or barriers to performance in sport. It would be interesting to compare the influence of cultural representations of disability sport across different disability groups; for example, visually impaired athletes or Boccia athletes with cerebral palsy. To facilitate larger scale quantitative studies, it would be useful to develop a questionnaire to assess SRM in disability sport. This can be achieved by selecting multiple measures representing the four social contexts of the model and subjecting the data to psychometric analysis to determine validity and reliability estimates. 


\section{CONCLUSION}

The social landscape of disability and disability sport is changing (Smith \& Perrier, 2015). With the change, the SRM can add value to sport and exercise psychology research. The psychological concepts in the SRM have little empirical evidence in sport; nonetheless this conceptualisation offers a forward thinking way of understanding the lived experience of reduced physical function in athletes. The implication of this study is that new evidence is available in support of the SRM as a heuristic to investigate participation in disability sport, and there is research value in further exploring the intersection of the disciplines; sport and exercise psychology and critical disability studies.

\section{ACKNOWLEDGEMENTS}

This study was part of an MSc Sport and Exercise Psychology dissertation of the lead author. The authors would like to thank the participants for taking part in the interviews.

\section{REFERENCES}

Ajzen, I., \& Madden, T. J. (1986). Prediction of goal-directed behavior: Attitudes, intentions, and perceived behavioral control. Journal of experimental social psychology, 22(5), 453-474.

Altmann, V. C., Hart, A. L., van Limbeek, J., \& Vanlandewijck, Y. C. (2014). Improvement of the classification system for wheelchair rugby: athlete priorities. Adapted physical activity quarterly, 31(4), 377-389.

Arnold, R., Fletcher, D., \& Daniels, K. (2016). Organisational stressors, coping, and outcomes in competitive sport. Journal of sports sciences, pp. 1-10.

Bandura, A. (1986). Social foundations of thought and action: A social cognitive theory. Englewood Cliffs, NJ: Prentice-Hall, Inc. 617 p.

Braun, V., \& Clarke, V. (2006). Using thematic analysis in psychology. Qualitative research in psychology, 3(2), 77-101.

Brittain, I. (2016). The Paralympic Games Explained. New York: Routledge.

Bury, M. (2001). Illness narratives: fact or fiction? Sociology of health \& illness, 23(3), 263-285.

DCAL (2015). Experience of sport and physical activity by adults in Northern Ireland. Continuous Household Survey Northern Ireland.

Deci, E. L., \& Ryan, R. M. (2000). The "what" and "why” of goal pursuits: Human needs and the self-determination of behavior. Psychological inquiry, 11(4), 227-268.

Goodley, D. (2013). Dis/entangling critical disability studies. Disability \& Society, 28(5), 631-644.

Goodwin, D., Johnston, K., Gustafson, P., Elliott, M., Thurmeier, R., \& Kuttai, H. (2009). It's okay to be a quad: Wheelchair rugby players' sense of community. Adapted physical activity quarterly, 26(2), 102-117.

Jaarsma, E. A., Dekker, R., Geertzen, J. H., \& Dijkstra, P. U. (2016). Sports participation after rehabilitation: barriers and facilitators. Journal of rehabilitation medicine, 48(1), 72-79.

Jaarsma, E. A., Dijkstra, P. U., Geertzen, J. H. B., \& Dekker, R. (2014). Barriers to and facilitators of sports participation for people with physical disabilities: A systematic review. Scandinavian journal of medicine \& science in sports, 24(6), 871-881.

Kittson, K., Gainforth, H. L., Edwards, J., Bolkowy, R., \& Latimer-Cheung, A. E. (2013). The effect of video observation on warmth and competence ratings of individuals with a disability. Psychology of Sport and Exercise, 14(6), 847-851. 
Litchke, L. G., Hodges, J. S., Schmidt, E. A., Lloyd, L. K., Payne, E., \& Russian, C. J. (2012). Personal meaning of Wheelchair Rugby participation by five male athletes. Therapeutic Recreation Journal, 46(1), 26.

Martin, J. J. (2008). Multidimensional self-efficacy and affect in wheelchair basketball players. Adapted Physical Activity Quarterly, 25(4), 275-288.

Martin, J. J. (2013). Benefits and barriers to physical activity for individuals with disabilities: a social-relational model of disability perspective. Disability and rehabilitation, 35(24), 2030-2037.

Norwich, B. (2002). Education, inclusion and individual differences: Recognising and resolving dilemmas. British Journal of Educational Studies, 50(4), 482-502.

Oliver, M. (2004). The Social Model in Action: if I had a hammer. In: C. Barnes \& G. Mercer (Eds.), Implementing the Social Model of Disability: Theory and Research (pp. 18-31). Leeds: The Disability Press.

Purdue, D. E. J., \& Howe, P. D. (2012). See the sport, not the disability: exploring the Paralympic paradox, Qualitative Research in Sport, Exercise and Health, 4(2), 189-205.

Reindal, S. M. (2008). A social relational model of disability: a theoretical framework for special needs education? European Journal of Special Needs Education, 23(2), 135-146.

Reindal, S. M. (2010). Redefining disability: a rejoinder to a critique. Nordic Journal of Applied Ethics, 4(1), 125-135.

Richardson, E. V., Smith, B. \& Papathomas, A. (2016). Disability and the gym: experiences, barriers and facilitators of gym use for individuals with physical disabilities. Disability and Rehabilitation. Sep 14, 1-8.

Shakespeare, T., \& Watson, N. (2001). The social model of disability: an outdated ideology? Exploring Theories and Expanding Methodologies, (2), 9-28.

Shirazipour, C. H., Sweet, S. N., Perrier, M. J., Ginis, K. M., \& Latimer-Cheung, A. E. (2015). "Supercrip" vs human interest: Examining stereotypes towards paralympians following the viewing of Canadian paralympic committee videos. Journal of Exercise, Movement, and Sport, 47(1).

Simpson, J., McMillan, H., \& Reeve, D. (2013). Reformulating psychological difficulties in people with Parkinson's disease: the potential of a social relational approach to disablism. Parkinson's Disease, 2013.

Smith, B. (2013). Disability, sport and men's narratives of health: A qualitative study. Health Psychology, 32(1), 110.

Smith, B., Bundon, A., \& Best, M. (2016). Disability sport and activist identities: A qualitative study of narratives of activism among elite athletes' with impairment. Psychology of Sport and Exercise, 26, 139-148.

Smith, B., \& Caddick, N. (2012). Qualitative methods in sport: a concise overview for guiding social scientific sport research. Asia Pacific journal of sport and social science, 1(1), 60-73.

Smith, B., \& Perrier, M-J. (2015). Disability, sport, and impaired bodies: a critical approach. In: R. J. Schinke \& K. R. McGannon (Eds.), The psychology of sub-culture in sport and physical activity: a critical approach (pp. 95-102). London: Psychology Press.

Smith, B., Perrier, M-J., \& Martin, J. J. (2016). Disability sport: A partial overview and some thoughts about the future. In: R. Schinke, K. R. McGannon, \& B. Smith (Eds.), Routledge international handbook of sport psychology (pp. 296-303). London: Routledge.

Smith, B., Tomasone, J. R., Latimer-Cheung, A. E., \& Martin Ginis, K. A. (2015). Narrative as a knowledge translation tool for facilitating impact: Translating physical activity knowledge to disabled people and health professionals. Health Psychology, 34(4), 303.

Stephens, C., Neil, R., \& Smith, P. (2012). The perceived benefits and barriers of sport in spinal cord injured individuals: a qualitative study. Disability and Rehabilitation, 34(24), 2061-2070.

Thomas, C. (1999). Female forms: Experiencing and understanding disability. London: McGraw-Hill Education (UK). 
Thomas, C. (2004). Rescuing a social relational understanding of disability. Scandinavian Journal of Disability Research, 6(1), 22-36.

Thomas, C. (2007). Sociologies of disability, 'impairment', and chronic illness: Ideas in disability studies and medical sociology. London: Palgrave.

Williams, T. L., Smith, B., \& Papathomas, A. (2014). The barriers, benefits and facilitators of leisure time physical activity among people with spinal cord injury: A meta-synthesis of qualitative findings. Health Psychology Review, 8(4), 404-425.

\section{APPENDIX A - INTERVIEW GUIDE}

1. What are the benefits of Wheelchair Rugby?

2. How do you think that different impairments restrict participation?

3. What social factors restrict participation in Wheelchair Rugby?

4. How would you promote the benefits of getting involved in Wheelchair Rugby?

5. What is it like to be around so many others who share your sport?

6. Has Wheelchair Rugby influenced how you see yourself and your capabilities?

7. How do you feel the general public view Wheelchair Rugby?

8. Do you think that para-sport gets treated differently to able bodied sport? How?

9. What personal factors help enable participation in Wheelchair Rugby?

10. What social factors help enable participation in Wheelchair Rugby?

11. How does access to sport facilities influence participation?

12. Are there any other factors that restrict participation in Wheelchair Rugby?

13. Have you ever felt excluded from opportunities in sport due to your impairment?

14. Do stigmatising attitudes affect participation in Wheelchair Rugby?

15. Do you see Wheelchair Rugby as elite sport or rehabilitation?

\section{APPENDIX B - DEDUCTIVE THEMATIC ANALYSIS - CODE BOOK}

\begin{tabular}{c|l|l}
\hline Code & $\begin{array}{l}\text { Social Relational Model } \\
\text { construct }\end{array}$ & $\begin{array}{l}\text { Description of social context (Thomas, 2007; Goodley, 2013; Smith \& Perrier } \\
\text { 2015) }\end{array}$ \\
\hline 1 & $\begin{array}{l}\text { Barrier - Direct social } \\
\text { interaction. }\end{array}$ & $\begin{array}{l}\text { The undermining of psycho-emotional well-being directly from negative interactions } \\
\text { directly with others (oppression). For example, (1) Being stared at by strangers } \\
\text { (2) Hearing oppressive jokes (4) Direct experience of (unintended or intended) hurt- } \\
\text { ful words (5) Being directly defined by disability (6) Direct negativity at the hands of } \\
\text { non-disabled people (7) direct over-medicalization. }\end{array}$ \\
\hline 2 & $\begin{array}{l}\text { Barrier - Direct experience } \\
\text { of attitudes and discourse. }\end{array}$ & $\begin{array}{l}\text { The undermining of psycho-emotional well-being directly from negative experiences } \\
\text { of societal attitudes and discourse. Stigmatisation as a result of unhelpful media and } \\
\text { cultural representation. (1) Tokenism (2) Viewing sport as rehabilitation (3) Assump- } \\
\text { tions about para-sport (4) The'super human'stereotype (5) Being viewed as passive, } \\
\text { frail or dependent (6) Being hailed as inspirational for doing recreational sport. }\end{array}$ \\
\hline 3 & $\begin{array}{l}\text { Barrier - Indirect; social } \\
\text { norms. }\end{array}$ & $\begin{array}{l}\text { The undermining of psycho-emotional well-being due to the experience discrimina- } \\
\text { tory social norms. For example, oppression from being excluded from opportunities. } \\
\text { This can arise from social relationships/experiences in areas such as employment, } \\
\text { education, transport, housing, health, welfare services and sports organisations. }\end{array}$ \\
\hline
\end{tabular}




\begin{tabular}{|c|c|c|}
\hline 4 & $\begin{array}{l}\text { Barrier - Indirect; built } \\
\text { environment. }\end{array}$ & $\begin{array}{l}\text { Structural 'disablism' due to power imposed by 'able-bodied' policies. The experience } \\
\text { of oppression from the built environment; for example, limited accesses to facilities } \\
\text { and services. Oppression arising from policies in areas such as employment, educa- } \\
\text { tion, transport, housing, health and welfare services, sports organisations. }\end{array}$ \\
\hline 5 & $\begin{array}{l}\text { Barrier - internalising neg- } \\
\text { ative cultural stereotypes. }\end{array}$ & $\begin{array}{l}\text { The undermining of psycho-emotional well-being as result of internalising (1) } \\
\text { Personal Tragedy Discourse (2) Abnormality Discourse (3) being positioned as inferior } \\
\text { (4) Defining themselves by disability (5) unfortunate individual (6) placing restric- } \\
\text { tions on themselves (7) adhering norms about disability. }\end{array}$ \\
\hline 6 & $\begin{array}{l}\text { Barrier - impairment } \\
\text { (Biological fact). }\end{array}$ & $\begin{array}{l}\text { The direct and immediate restrictions due to impairment, e.g. pain, discomfort, sec- } \\
\text { ondary health conditions, fatigue.. If all oppressive attitudes and restrictive barriers } \\
\text { were removed these experiences would remain real. }\end{array}$ \\
\hline 7 & $\begin{array}{l}\text { Barrier - Impairment } \\
\text { effects (Social). }\end{array}$ & $\begin{array}{l}\text { Direct and immediate effects of biological restriction in contemporary society; things } \\
\text { that you can't do because of impairment, e.g. transfer into chairs, drive. }\end{array}$ \\
\hline 8 & $\begin{array}{l}\text { Facilitator - impairment } \\
\text { (social). }\end{array}$ & $\begin{array}{l}\text { The effects of social'additionality' on physiology and psychology at a micro level. } \\
\text { This can be in the form of formal (rehab programmes) or informal (teammates/ } \\
\text { volunteers) care. For example, the effect of sport on health and strength. Changes } \\
\text { at a micro level that promotes participation (Cures, therapy, interventions, physical } \\
\text { adjustments, technology). }\end{array}$ \\
\hline 9 & $\begin{array}{l}\text { Facilitator - psycho-emo- } \\
\text { tional well-being. }\end{array}$ & The enhancing of psycho-emotional well-being (self-esteem \& confidence). \\
\hline 10 & $\begin{array}{l}\text { Facilitator - Indirect - } \\
\text { changes to structural } \\
\text { environment. }\end{array}$ & $\begin{array}{l}\text { Macro level changes in the structural environment due to inclusive policies. For ex- } \\
\text { ample, increased access to facilities and services (progressive and inclusive policies). } \\
\text { From policies in areas such as employment, education, transport, housing, health } \\
\text { and welfare services, sports organisations. }\end{array}$ \\
\hline 11 & $\begin{array}{l}\text { Facilitator - indirect; } \\
\text { changes to social norms. }\end{array}$ & $\begin{array}{l}\text { Changes in social norms resulting in increased opportunities for people with } \\
\text { disabilities. This can arise form social relationships/experiences in areas such as } \\
\text { employment, education, transport, housing, health, welfare services and sports } \\
\text { organisations. }\end{array}$ \\
\hline 12 & $\begin{array}{l}\text { Facilitator - Direct; changes } \\
\text { to attitudes and discourse. }\end{array}$ & $\begin{array}{l}\text { Changes in societal attitudes and discourse as a result of shifting media and cultural } \\
\text { representation. (1) para-sport as sport and not rehabilitation (2) the sport not the } \\
\text { person (3) changes in stigmatisation of people with disabilities. }\end{array}$ \\
\hline 13 & $\begin{array}{l}\text { Facilitator - Direct; social } \\
\text { interaction. }\end{array}$ & $\begin{array}{l}\text { The enhancing of psycho-emotional well-being directly from positive interactions } \\
\text { with others. For example, (1) Sports people (3) families (4) positive discourse } \\
\text { (5) being defined as an athlete (6) medical staff (8) educational staff. }\end{array}$ \\
\hline
\end{tabular}

